\title{
ECONOMIC DEVELOPMENT AND HUMAN VALUES - THE NEED TO GO HAND IN HAND
}

\author{
NITIKA \\ Economics, Khalsa College for Women, Civil Ines, Ldh, Punjab, India
}

Economic development has its changed definition today. In recent years, Economic development means improvement in Health facilities, Educational facilities, Improvement in Overall Quality of Life/Standard Of Living along with increase in Per capita income. Economic development should also be defined in terms of reduction in Malnutrition, Diseases, Illiteracy, Unemployment, Inequality and especially and most importantly decrease in HUMAN VALUES. Now, our aim is to Correlate Economic Development with Human values. Human values are a set of consistent behaviour and measures that guide human being is in doing what is right and acceptable by the society. The Objectives of the Study includes that there exists a Negative Correlation between increased Educational reforms, Industrialization, Drug, Health, Pharmaceutical industries respectively and National and Per capita income with the Human Values. To study the Objectives, Secondary tools were used, which includes Books, Journals, Newspapers, Internet, Google Scholar. This study was carried out with the help of various Case-Studies be it on the increase of Mall-Culture, the case study of ban on Ranbaxy, on the implication of constructing malls, increasing prices, declining per-capita income and increasing disparity rates. Also, the implications of Industrialization, Privatization,

Globalization comes out to be more Negative, which proves our Objectives and Hypothesis as correct. However, there is a ray of hope and Positive Effects also exists, but there is a need to carry out human values along with our Economic Progress. (BE IT GROWTH OR DEVELOPMENT)

KEYWORDS: Human Values, Education, Drug, MNC's, Corruption \& BRIBERY
\end{abstract}

Received: Jun 05, 2017; Accepted: Jun 25, 2017; Published: Jul 06, 2017; Paper Id.: IJECRAUG20174

\section{INTRODUCTION}

"Man's mind, once stretched by a new idea, never regains its original dimensions".

\section{-OLIVER HOLMES}

"Economic Growth may one day turn out to be curse rather than a good, and under no conditions can it either lead into freedom or constitute a proof for its existence".

\section{-HANNAHARENDT}

Economic development is the sustained, concerted effort to promote standard of living and

promote economic health of a specific area. It includes development of human capital, critical infrastructure, regional competitiveness, environmental sustainability, social inclusion, health, safety, literary,

AMARTYA SEN points out "Economic growth is one aspect of economic development".

Economic development inculcates in it GLOBALIZATION, INDUSTRIALIZATION, MODERNIZATION. 
Origin of the concept still undefined but its closely bound up with the evolution of CAPITALISM and the DEMISE OF FEUDALISM.

Economic development is a purely technical word, a well defined term of economics and we have tried to make its relationship, try to understand the relationship of economic development with an ethical, philosophical word "HUMAN VALUES."

In general, if we say, "HUMAN VALUES are a set of consistent behaviours and measures that guide human beings in doing what is right and acceptable by the society. It also includes dignity, respect and appropriateness among people. Human values are used to set laws in most cases."

Now, the question is "ECONOMIC DEVELOPMENT" purely practical, technical word and its relationship with a philosophical, ethical and a very sensitive word "HUMAN VAUES". Does there exists a relationship between them?

\section{OBJECTIVES OF THE STUDY}

- There exists a negative relationship between increased educational reforms in north-West India and human values (declining).

- $\quad$ There is a negative correlation between increased Industrialization in north-west India and existing human values.

- Increased drug industry and pharmaceutical industry has lead to decreased human values.

- There also exists a relationship between increase and decrease of national income, per capita income with human values

\section{RESEARCH METHODOLOGY}

- Secondary tools are used to collect the information.

- Use of BOOKS, JOURNALS, NEWSPAPERS, INTERNET is being done to collect the relevant information and the vital statistics.

\section{DESCRIPTION OF THE OBJECTIVES}

Article 45 of our constitution states "Free and compulsory education for all children up to the age of fourteen years. If we focus on north-west India.

- In in Punjab, SARV-SIKHIYA, ABHIYAN is an attempt.

- Distant education center in Delhi- IGNOU which is extending itself throughout India.

- Increased number of research centers throughout north-west India.

If we have a small look at the total number of colleges in Punjab itself, there is a huge increase

Arts and science colleges $=64$ (World information colleges)

Dental Colleges $=13$

Law Colleges $=22$ 


$$
\begin{aligned}
& \text { Medical Colleges }=07 \\
& \text { Nursing Colleges }=18 \\
& \text { Engineering Colleges }=74 \\
& \text { Management Institutions = } 41 \\
& \text { Polytechnic Colleges }=7 \\
& \text { Pharmacy Colleges }=22 \\
& \text { Ayurvedic Colleges }=09
\end{aligned}
$$

These colleges are providing multiple courses under one roof which has lead to less BRAIN DRAIN.

- It has generated increased employment opportunities. More colleges, more teachers, more people getting employed.

- $\quad$ People who are doing job are managing their studies with the help of DISTANT EDUCATION.

- Persuing technical courses like B. tech, M. tech, MCA, BCA, BBA has become quite easy by opening of private institutes.

- These all efforts have increased the Quality of Education.

\section{\#BU'T STILL THERE ARE DECLINING HUMAN VALUES}

- Colleges and many educational institutes have just become commercial centers, getting huge fees and giving desired degrees in return.

- It has lead to "WHITE COLLAR UNEMPLOYMENT"

- White collar unemployment in return is taking our youth to Depression and drug addiction.

- This all is resulting in increased suicide ideation.

In a study done by ANDERSON \& SMITH (2005), its been found that Suicide is the third leading cause of death among 15-24 years and depression is mostly the associated factor.

\section{Increased Industrialization has also Lead to Decreased Human Ethics}

CASE STUDY-CHANDIGARH, the city beautiful is at its fullest in term of the development. New MALLS are being inaugurated, MULTINATIONAL FIRMS are inaugurated, AIRPORT inaugurated by P.M Narandra Modi on 11 Sept, 2015 in MOHALI. Opening of MNCS is of course a good sign, because it's generating employment opportunities, increasing standard of living and decreasing brain-drain phenomenon,

\section{\#BUT WHAT ABOUT ITS NEGATIVE IMPACTS? HUMAN VALUES HAVE SUFFERED ALOT IN THIS RACE}

Declining small-scale and cottage industries is the main cause of this growth.

MY MONEY-NOT COUNTRY'S MONEY, PROFIT AT THE COST OF THE HUMANITY is being focussed, 
CORRUPTION, DISHONESTY, BRIBERY all getting promoted.

According to the PSYCHOLOGICAL STUDY, MALL CULTURE has lead to Space congestion, Growing traffic, Developing infrastructural pressure, Power scarcity, Parking blues. These commercial havens not only serve as battlegrounds for International brands, but also carried away in the voluble streams of Consumerism and Retail Revoltion. Common man is rendered completely unarmed. He is being prepared to take what can be actually termed as SWEET POISON, which in a way is suitable to Indian Economy, but on the other hand can steal away the joy and innocence from daily life.

\section{DRUG INDUSTRY AND PHARMACEUTICAL INDUSTRY INCREASE ALSO SHARES A NEGATIVE RELATIONSHIP WITH HUMAN VALUES}

The pharmaceutical industry in India is the world's third largest in terms of Volume. According to Ministry of Chemicals and Fertilizers, the total turnover of India's pharmaceutical industry between 2008 and 2009 was 21.04 US billion \$. The Indian Pharmaceutical market is likely to grow at a compound annual growth rate of $14-17 \%$ in between 2012-16. The pharmaceutical Industry in India ranks $3^{\text {rd }}$ in his world terms of volume and $14^{\text {th }}$ in the term of value.

\section{Various Govt. Programmes Like}

- $\quad$ Distributing free iron tablets for girls in schools esp. in Punjab.

- $\quad$ Badal govt, has opened mobile van services $24 * 7$

- No of hospitals, no. of dispensaries, no. of medical camps for free eye checkups and for monitoring health has increased comparatively in Punjab.

\section{But Still HUMAN ethics are Far Behind in the Race}

- Drugs that are being provided to distribute free of cost to children are being sold to the chemists.

- Drugs without expiry date are sold freely.

- $\quad$ RANBAXY, being caught by WHO, selling adulterated medicine.

- Human life, importance of human being has declined in this race of competitiveness.

\section{NATIONAL INCOME AND PER- CAPITA INCOME AND ITS RELATIONSHIP WITH HUMAN VALUE}

Growth Rate

\begin{tabular}{|c|c|}
\hline Years & Growth Rate \\
\hline $2014-15$ & $7.18 \%$ \\
\hline $2015-16$ & $7.6 \%$ \\
\hline $2016-17$ & $7.1 \%$ \\
\hline
\end{tabular}

- Decreased national income and per capita income indicates that a common- man is still a sufferer.

- Disparity is increasing, rich getting richer and poor getting poorer,

- $\quad$ Rich people spending their savings on luxury goods, not on capital-formation, that's why it's not contributing towards the economic growth. 
As we see, rich people have done nothing to increase economic development, although the standard of living of rich people has increased. Each have 2-3 cars, their own big banglaws, spend their money on Luxurious goods. But, what about their contribution to the economic Development?

On the other hand, poor people had no money to fulfil their basic needs. They did not get Subsistence wages. People are dying, because of Unavailability of Food and other basic goods. Due to these reasons, people get indulged in corruption and unethical activities.

\section{IMPLICATIONS AND CONTRIBUTIONS}

The points discussed above have made us to think about both the sides of the coin. The economic development, increased industrialization, globalization, drug industry and educational opportunities have taken our country ahead, especially the North-west region to a progressive path, but we have the reasons to worry as well, because human values, the value of a human life, emotions, common- ethics, moral values have lacked far behind.

So, it should be focused that progress also carries the humanity, the human values with it.

\section{REFERENCES}

1. En.m. Wikipedia.org/wiki/Economic

2. En.m. Wikipedia.org/wiki/Pharmaceutical

3. Google Scholar

4. Its "India Calling" for global pharmaceutical companies, says a Price Water house coopers report.

5. Pharma to Topple IT as big paymaster". THE ECONOMICTIMES, 8 June, 2010.

6. "Sen, A. (1983). Development: Which Way Now? Economic Journal, Vol. 93,

7. Issue 372. pp. 745-762.

8. Wikipedia.com

9. World colleges information (www.worldcolleges.info $)$ 
